\title{
Correction to: Adverse Events with D-penicillamine Therapy in Hepatic Wilson's Disease: A Single-Center Retrospective Audit
}

\author{
Sanjay Kumar ${ }^{1}$ Biswa Ranjan Patra ${ }^{1} \cdot$ Mohammed Irtaza $^{1} \cdot$ Praveen Kumar Rao $^{1} \cdot$ Suprabhat Giri $^{1} \cdot$ Harish Darak $^{1}$. \\ Amrit Gopan ${ }^{1} \cdot$ Aditya Kale $^{1} \cdot$ Akash Shukla $^{1}$ D
}

Published online: 23 February 2022

(c) Springer Nature Switzerland AG 2022

\section{Correction to: Clinical Drug Investigation https://doi.org/10.1007/s40261-022-01117-x}

The original version of this article unfortunately contained a mistake.

Abstract—Results: 3rd sentence, which previously read:

Of the 28 AEs, severe AEs leading to permanent D-penicillamine discontinuation occurred in $16(57 \%)$ [never reintroduced $12(43 \%)$, discontinued after intolerant to rechallenge, $4(14 \%)]$, temporary cessation followed by reintroduction to initial dose $13(46 \%)$ and continuation with reduced dose in $3(11 \%)$ patients.

Should read:

Of the $28 \mathrm{AEs}$, severe AEs leading to permanent D-penicillamine discontinuation occurred in $16(57 \%)$ [never reintroduced $12(43 \%)$, discontinued after intolerant to rechallenge, $4(14 \%)$ ], temporary cessation followed by reintroduction to

The original article can be found online at https://doi.org/10.1007/ s40261-022-01117-x.

Akash Shukla

akash@kem.edu; drakashshuka@yahoo.com

Sanjay Kumar

sanjaykumar@kem.edu

Biswa Ranjan Patra

biswa.patra@kem.edu

Mohammed Irtaza

mohammedirtaza@kem.edu

Praveen Kumar Rao praveenkumarrao@kem.edu

Suprabhat Giri suprabhatgiri@kem.edu initial dose 9 (32\%) and continuation with reduced dose in $3(11 \%)$ patients.

Table 1: Column 1, row 28, which previously read:

Total protein $(\mathrm{mg} / \mathrm{dL})$

Should read:

Total protein $(\mathrm{g} / \mathrm{dL})$

Table 1: Column 1, row 29, which previously read:

Serum albumin (mg/dL)

Should read:

Serum albumin $(\mathrm{g} / \mathrm{dL})$

Table 3: Column 1, row 29, which previously read:

Total protein $($ mean $\pm \mathrm{SD})(\mathrm{mg} / \mathrm{dL})$

Should read:

Harish Darak

harishdarak@kem.edu

Amrit Gopan

amritgopan@kem.edu

Aditya Kale

adityapkale@kem.edu

1 Department of Gastroenterology, Seth GS Medical College and KEM Hospital, Gastroenterology Office, 9th Floor, New Building, Parel, Mumbai 400012, India 
Total protein $($ mean $\pm \mathrm{SD})(\mathrm{g} / \mathrm{dL})$

Table 3: Column 1, row 30, which previously read:

Serum albumin (mg/dL) Median (IQR)

Should read:

Serum albumin (g/dL) Median (IQR) 